\title{
El mensaje de la gracia. Vida de María y vocación de la Iglesia"
}

\author{
Gianni Colzani**
}

Recibido: 23 de noviembre de 2014 • Aprobado: 21 de diciembre de 2014

\section{Resumen}

El tema de este artículo es muy amplio y, por eso, necesita algunas precisiones. Se trata de repensar toda la soteriología cristiana, desde el punto de vista mariano y mariológico y, aunque no se explicita directamente, se trata de hacerlo en el contexto de nuestro tiempo y de la vida eclesial actual.

Probablemente, a ninguna dimensión de la vida cristiana le interesa tan directamente la comprensión que las personas tienen de sí mismas en cuanto la soteriología, y; sin embargo, ningún otro aspecto de la fe resulta tan difícil y extraño al sentir común como el don de la salvación (Werbick, 1990)ํ. Para explicar este desinterés respecto a la soteriología cristiana, se deberían recordar muchos factores ${ }^{2}$, pero el punto decisivo se refiere a la interpretación de

1 Hablando de esta crisis, el autor habla de una redención sin redentor y de un proyecto de vida secularizado, alternativo al cristiano. Speaking of this crisis, the author speaks of a Redeemer and redemption without a draft secularized alternative to the Christian life. En évoquant cette crise, l'auteur parle de la rédemption sans rédempteur et d'un projet de vie sécularisé, alternatif au chrétien.

2 Werbick recuerda un clima cultural complejo, que incluye la crisis de la ética y el ocaso del sentido del pecado, el sentido del misterio reencontrado y un renacimiento de la religión; aunque verdaderas, me parece que estas observaciones remiten a experiencias que son todavía

* Este es un producto de la investigación del autor.

* Sacerdote de la diócesis de Milán. Doctor el teología de la Facultad teológica de Milán (1971). Actualmente es profesor de misionología de la Pontificia Universidad Urbaniana de Roma. Correo electrónico: g.colzani@urbaniana.edu; gianni64colzani@gmail.com 
la vida ingenuamente atribuida a la concepción cristiana. No pocos interpretan la salvación cristiana basándola en un escenario oscuro y negativo, el de un mundo dominado por el pecado y por sus expresiones de violencia, maldad, injusticia, inmoralidad; por medio de los castigos y el don de la gracia, Dios educaría a la humanidad y la introduciría progresivamente en la vida que a Él le place.

Palabras clave: Marilogía, soteriología, iglesia, gracia.

\title{
The message of grace - Mary's life and vocation of the Church
}

\begin{abstract}
The topic of this article is very broad and, therefore, needs some clarification. It is about rethinking the entire Christian soteriology, from the Mariology and Marian point of view and, although not directly explicit, this is done in the context of our time and current ecclesial life.

Probably, no dimension of Christian life is so directly interested in the understanding people have of themselves as soteriology, and; however, no other aspect of faith is as difficult and strange to the common feeling as the gift of salvation (Werbick, 1990). To explain this lack of interest regarding the Christian soteriology, many factors should be remembered, but the key point relates to the interpretation of life naively attributed to the Christian conception. Not few interpret Christian salvation basing it on a dark and negative scenario of a world dominated by sin and its expressions of violence, evil, injustice, immorality; through punishment and the gift of grace, God would educate humanity and would progressively introduce it in the life that pleases Him.
\end{abstract}

Keywords: Mariology, soteriology, church, grace.

poco críticas y demasiado disponibles a cualquier contenido y a cualquier personaje para que sean realmente significativas. Werbick remember a complex cultural climate, including the crisis of ethics and the decline of the sense of sin, the sense of mystery and rediscovered a revival of religion; but true, it seems to me that these comments are to experiences that are still available too uncritical and any content and any character to be really significant. Werbick tient à rappeler un climat culturel complexe qui inclut la crise éthique et le déclin du sens su péché, le sens du misère retrouvé et une renaissance de la religion; cependant, il me semble que ces observations font allusion à des expériences peu critiques et trop disponibles face à n'importe quel contenu et personnage pour qu'elles soient réellement significatives. 


\section{Le message de la grâce - Vie de Marie et vocation de l’Eglise}

\section{Résumé}

Le thème de cet article est très vaste et pour cela, il demande quelques précisions. Il s'agit de repenser toute la sotériologie chrétienne, du point de vue marial et mariologique et, bien qu'il ne soit pas directement explicite, on essaye de l'inscrire dans le contexte actuel et la vie ecclésiale actuelle.

Probablement, aucune dimension de la vie chrétienne ne s'intéresse si directement à la compréhension que les personnes ont de soi-même par rapport à la sotériologie, et, malgré cela, aucun autre aspect de la foi n'est si difficile et étrange que le don du salut (Werbick, 1990). Pour expliquer ce manque d'intérêt par rapport à la sotériologie chrétienne, on devrait rappeler plusieurs facteurs, mais le point décisif fait référence à l'interprétation de la vie naïvement attribuée à la conception chrétienne. Beaucoup de personnes interprètent le salut chrétien comme un scénario sombre et négatif d'un monde dominé par le péché et ses expressions de violence, le mal, l'injustice, l'immoralité; par la punition et le don de la grâce, Dieu éduquerait l'humanité et instaurerait progressivement la vie qui Lui plaît.

Mots-clés: Mariologie, sotériologie, Eglise, grâce.

\section{Introducción}

Esta visión ética del cristianismo siempre ha sido ampliamente criticada. No pocos han visto en esta visión un intimismo individualista que considera la salvación como una cuestión interior relacionada con el alma y, eventualmente, con el mundo futuro, pero no con esta vida y con esta tierra ${ }^{3}$ (Bosch, 1991); una tal perspectiva ha sido acusada de abstracción y de falta de sentido histórico y se la vincula con aquella antropología escolástica de los dos fines y a la teología de los dos planos; natural y sobrenatural, que hoy ya no se aceptan. Encontramos aquí un esfuerzo por superar la herencia de un pasado que se valía tanto de la tradición agustiniana y de su visión de la gracia -gracia actual-como don y como ayuda, como de la enseñanza del tridentino y de su visión de la gracia -gracia

3 Bosch habla de una individualización y de una "eclesiastización" de la salvación, que el autor hace remontar a la mitad de la época patrística. 
habitual- como habitus. La superación de este esquema ha llevado a ver en la referencia cristológica el fundamento de todo discurso sobre la gracia: en todas sus manifestaciones, la gracia es gratia Christi ${ }^{4}$.

Hay que considerar este cambio de la teología de la gracia como algo pacífico que ha llevado tanto a un cambio de la teología de la historia (Meis, 1990), vista como historia universal de la salvación, como a una renovación de la antropología, evidente en las reconstrucciones bibliográficas de los años 90 (Colzani, 1993). En la práctica, el abandono de una teología del sobrenatural, construida como pura gratuidad en base al concepto de naturaleza pura, ha comportado notables consecuencias; ha asumido un primer plano la gracia increada, es decir, la presencia y la obra del Espíritu Santo, del que hay que buscar una comprensión más existencial e histórica.

Con razón, $\mathrm{H}$. Mühlen ha criticado el carácter individual de una teología de la gracia entendida como iustificatio impii y ha pedido una comprensión más relacional de la gracia; esto le ha llevado a retomar el vínculo entre eclesiología y pneumatología, a volver a utilizar el lema tomista de la Iglesia como una mystica persona, y a desarrollar no solamente la acción santificadora de la Iglesia en sus miembros, sino también ese papel público que la Iglesia reviste ante la humanidad toda entera (Mühlen, 1972). Yendo más allá de aquella «peregrinación de la fe» con la que María ha acompañado fielmente la vida del Hijo, perseverando en comunión con Él hasta la «dolorosa compasión» de la cruz (LG, 58) ${ }^{5}$, Mühlen se remonta a la estructura personal y óptica de María - estructura que precede todo consenso y del que éste deriva- y, distinguiendo entre santidad de consagración y santidad de santificación, habla de una "consagración" tal por la cual María está al servicio de la obra redentora de Cristo (Mühlen, s.f.). Inserta como compago socialis en la vida y en la historia de la humanidad, a la Iglesia -animada por el Espíritu- le corresponde la tarea de mostrar «la dimensión constitutivamente "pública", es decir, relacionada con la entera sociedad humana, de la teología de la gracia (Mühlen, s.f.).

Pero será Y. Congar quien presentará una gran síntesis de eclesiología y de pneumatología. En la vida trinitaria, el Espíritu se manifiesta como la energía

4 También aquí me limito a recordar un trabajo mío: G. COLZANI, Antropología Teológica. El hombre: paradoja y misterio [1997], Secretariado Trinitario, Salamanca 2001.

5 María «antecede con mucho» toda otra criatura tanto que es, sí, miembro de la Iglesia, pero «miembro sobreeminente y del todo singular»; por eso es, justamente, «su prototipo y modelo destacadísimo [de la Iglesia] en la fe y caridad». 
divina que abre las personas trinitarias hacia lo que está fuera, a lo que es lo otro: por eso es el amor y el don. El Espíritu «es el éxtasis de Dios hacia su "otro": la criatura» (Duquoc, 1977) ${ }^{6}$. Y es quien guía hacia el perfeccionamiento de esta apertura por medio de la comunicación y del compartir. Desarrollando la obra del Espíritu respecto a la Iglesia en términos de una transformación sacramental que se realiza por medio del don eucarístico de la vida de comunión, y la epíclesis que invoca y solicita la obra del Espíritu, Congar ve la Iglesia como «memoria del acontecimiento fundador, signo profético del porvenir absoluto, gracia presente que nace de este futuro y que lo prepara» (Congar, s.f.). Es dentro de estos profundos cambios donde tenemos que colocar la figura de María.

En un contexto cultural en el que se va imponiendo un humanismo escéptico respecto a los presupuestos religiosos de la dignidad de la persona, la crisis de la gracia corre el riesgo de llevar a una crisis de la presencia de la Iglesia en una tal sociedad, y a una marginalización de la piedad mariana. El mismo Juan Pablo II ha debido admitir que, en nuestro tiempo, se ha dado «una secularización gradual de la salvación», con el consiguiente riesgo de «reducir el cristianismo a una sabiduría meramente humana» $(\mathrm{RM}, 11)$. La piedad mariana nos puede liberar de estos equívocos; nadie como María ha reconocido el carácter personalístico de la gracia -no es algo, sino Dios mismo- y nadie como María se ha dejado implicar en un diálogo de amor con el Dios de la gracia y en una respuesta comprometida en grado de empeñar toda la vida.

\section{María, Madre en el orden de la gracia}

Las Escrituras han iluminado el hesed, la benevolencia, la gracia con la que Dios sigue la vida de cada hombre y, de manera particular, la historia de Israel; además, esta «gracia salvadora de Dios» para todos los hombres, ha aparecido en Jesús para ayudarnos a abandonar toda impiedad, a vivir según la justicia y la piedad, y a perseverar aguardando la feliz esperanza de su vuelta gloriosa (Tt 2, 11-13). También María entra en esta historia de gracia con un título sobreeminente: «unida también íntimamente a la Iglesia, la Madre de Dios es tipo de la

6 En su esfuerzo por volver a pensar la realidad de Dios más allá de la lógica de la identidad, pero según la diferencia, Ch. Duquoc discute la figura del narcisismo y la del "cara a cara" para comprometer a Dios en una pasión por la criatura: ivi, pp. 116-119. 
Iglesia, orden de la fe, de la caridad y de la perfecta unión con Cristo. Porque en el misterio de la Iglesia que con razón también es llamada madre y virgen, la Bienaventurada Virgen María la precedió, mostrando en forma eminente y singular el modelo de la Virgen y de la Madre» (LC, 63).

Sin seguir todo este discurso, ya magistralmente indicado por la Lumen Gentium y Redemptoris Mater, podemos recordar el esfuerzo conciliar de síntesis allí donde presenta

María como «Madre en el orden de la gracia»: esta expresión viene al final de un texto -Lumen Gentium $61^{7}$ - muy denso, tanto que el entero número 62 puede ser visto como su explicación. G. Philips indicará el sentido de este título mariano en la fidelidad de María «en el aceptar el plan de salvación tal como Dios ha querido realizarlo» (Philips, 1967); este sentido, muy amplio, permitirá al Concilio, por una parte, valorizar «el consenso prestado con fe» por Maria en toda su vida y, por otra, subrayar «la caridad de madre» con la que cuida los discípulos del Hijo. Para evitar todo malentendido, el Concilio recordará que ninguna criatura puede «compararse jamás con el Verbo Encarnado nuestro Redentor», pero observará que «la única mediación del Redentor no excluye, sino que suscita en sus criaturas una múltiple cooperación que participa de la fuente única». Consecuentemente, la función de María es «una función subordinada», cuyo objetivo es unir más íntimamente a los fieles con su único Salvador.

En este sentido, la maternidad de María no es la historia privada de una mujer joven, sino que es un acontecimiento que forma parte del designio mesiánico de Dios ${ }^{8}$; no es un caso que el Concilio haya precisado esta singularidad, observando que «predestinada, junto con la Encarnación del Verbo, desde toda

7 Transcribo todo el texto de Lumen Gentium 61: «La Santísima Virgen, predestinada, junto con la Encarnación del Verbo, desde toda la eternidad, cual Madre de Dios, por designio de la Divina Providencia, fue en la tierra la esclarecida Madre del Divino Redentor, y en forma singular la generosa colaboradora entre todas las criaturas y la humilde esclava del Señor. Concibiendo a Cristo, engendrándolo, alimentándolo, presentándolo en el templo al Padre, padeciendo con su Hijo mientras El moría en la Cruz, cooperó en forma del todo singular, por la obediencia, la fe, la esperanza y la encendida caridad en la restauración de la vida sobrenatural de las almas. por tal motivo es nuestra Madre en el orden de la gracia».

8 Encontramos esta dimensión universal en Lc 1, 30, donde las palabras del ángel que expresan la maternidad de María -has encontrado gracia delante de Dios- están tomadas de Ex 33, 12-17; en este texto, Moisés no se contenta con el ángel que Dios promete en Ex 33, 2, sino que pide, por una parte, «conocer a Dios» (v. 13), y, por otra, que Dios mismo «camine con su pueblo» (v. 15). Solamente este encuentro entre la presencia Salvadora de Dios y el deseo de conocerlo, «dará reposo» (v. 14). Utilizando este lenguaje, Lucas indica en la maternidad de María el vértice de una historia de la que es protagonista el mismo Dios. 
la eternidad, cual Madre de Dios, por designio de la Divina Providencia, fue en la tierra la esclarecida Madre del Divino Redentor» y que, de esta manera, ella «cooperó en forma del todo singular» en la obra del Salvador (LG, 61). La comprensión de este hecho no se agota en María, sino que se debe remontar a aquél Dios que, aun no teniendo ninguna necesidad de colaboraciones humanas, ama servirse de personas justas; consiguientemente, María no es «causa de lo que sucede, sino solamente condición libremente asumida por Dios, y signo de la prodigiosidad del nuevo inicio» (Forte, 1989).

Por esto es posible leer esta maternidad en los términos de la pietas humana; comentando Lc 1, 38, es decir, las palabras finales del relato de la anunciación, Schürmann escribirá que «la palabra de María siempre ha tenido una importancia fundamental para la reflexión piadosa, que la ha entendido como punto culminante de todo comportamiento religioso ante Dios, porque ésta expresa de la manera más elevada la disponibilidad pasiva unida a la prontitud activa, el vacío más profundo que se acompaña con la plenitud más grande» (Schürmann, 1983). La palabra de María -la última del relato- es, sencillamente, dejarlo todo en las manos de Dios, un confiarse totalmente a Él. Hay que tener en cuenta esta implicación de las personas divinas.

\subsection{La autocomunicación del Verbo de vida}

A los creyentes les ha parecido algo único y excepcional lo que se ha dado en la maternidad de María: lo han vinculado con la plenitud de los tiempos (Gal 4, 4-7); porque, gracias a aquél acontecimiento, las personas han podido dirigirse a Dios como al Abbá. Debemos volver al sentido primario de la gracia, y recordar que esta maternidad «habla más de Dios que de María, más de quien concede la gracia que de quien la recibe [...]. Sin esta referencia, gracia puede terminar por indicar, insensiblemente, su contrario, es decir, el mérito» (Cantalamessa, 1989). Lugar de manifestación del Verbo, la humanidad de Jesús expresa la realidad de la vida divina y la expresa en el don que el Verbo de vida da de sí a la humanidad.

Una fe que aplique su pregunta de inteligencia a este acontecimiento no puede no reconocer la inadecuación del logos griego y de su visión elaborada en torno a una noción de "ser" de tipo cosmológico; se entra en sintonía con este acontecimiento solamente, a través del Verbo de la vida. A este respecto, merece una mención la sugerencia de J. Moltmann que invita a desarrollar «un ordo salutis 
enteramente orientado hacia el concepto de vida» (Moltmann, 1991) ${ }^{9}$; los límites de su posición no pueden hacer olvidar que, para las Escrituras, el Verbo ha venido para que los hombres «tengan vida y la tengan en abundancia» (Jn 10,10; Cor 15, 45), y que el último Adán -es decir, Cristo- es presentado como «espíritu donador de vida». En las Escrituras, además, el camino de la vida de Jesús es un camino hacia la vida, es un camino en el que las esperanzas y las concepciones de los contemporáneos han sido acogidas y confirmadas, pero también criticadas y superadas (Gutiérrez, 1992); en el centro se encuentra la Pascua como vértice de aquella libertad y de aquél amor divino que da la vida para después recobrarla de nuevo, sin que ninguno se la pueda quitar (Jn 10, 17-18).

En esta perspectiva, la plena revelación de Dios y la comunicación de su gracia pasan a través de la mediación de ese Jesús que une en sí mismo aquél amor divino en el cual el Hijo se posee como don, y aquella incondicionada libertad humana ${ }^{10}$ que capta su sentido último no en la posesión de cosas, sino en una relación personal que corre riesgos, donde experimentarse en un diálogo de amor que, experimentándose amado, corresponde al amor. De esta manera, aquella incondicionada libertad humana, que Dios mismo respeta, se realiza a través de una relación, del encuentro con el otro: mientras lo percibe en su alteridad y aprecia la diferencia entre el propio "yo" y el otro, experimenta también que se puede realizar en la propia libertad solamente reconociendo la libertad de los otros, y relacionándose con esa libertad como ámbito para la realización para la propia, apuntar a un proyecto social donde se camine juntos, los-unos-con-los-otros, los-unos-para-los-otros.

De esta manera, entrando en la historia humana, y entrando en ella como «plenitud de gracia y de verdad» (Jn 1, 14), Jesús provoca la libertad humana con su invitación (Mc 1, 17. 20; Jn 1, 38-39), pero, al mismo tiempo reconoce la incondicionalidad de esa libertad con aquella pregunta: - ¿También vosotros queréis marcharos? (Jn 6,67)- que sigue al reconocimiento de la presencia activa

9 Sin embargo, el desarrollo que formula Moltmann no puede no suscitar perplejidad; después de haber examinado la noción de vitalidad, el conflicto entre espíritu y carne, una lectura apocalíptica y la autotrascendencia humana, concluye en una "espiritualidad de la vida contra la muerte". «La vida en el Espíritu es vida contra la muerte: no contra el cuerpo, sino en favor de su liberación y transfiguración. Decir sí a la vida significa decir no a la guerra y a sus devastaciones...» (Ivi, p. 118).

10 El carácter incondicionado de la libertad humana está en el hecho de que, incluso ante Dios, la libertad de la criatura mantiene una identidad que no se deja disolver; en este sentido, la superación de sí mismos, y la vuelta en sí mismos se entrelaza continuamente con la gracia y con el desafío, mientras ella misma es desafiada. 
de la gracia: «nadie puede venir a mí si no se lo concede el Padre» (Jn 6, 65). Solamente Dios puede introducir a Dios. En la práctica, la economía divina comprende la entera historia humana, y nos recuerda a todos que la forma más alta del poseerse es el darse; la gracia, es decir, la singular relacionalidad que Dios instituye con la humanidad, es el dono que -con Cristo- revela el secreto último de la vida. Resumida en la Pascua, la entera vida de Jesús recuerda cómo la libertad de Dios se expresa en el ágape y en la kénosis: el ágape que se hace apertura y don para el otro es el contenido, mientras que la kénosis es la forma de la libertad divina.

La maternidad de María no es solamente su cercanía particular a Jesús, sino que es -como cada mamá sabe muy bien- una verdadera y propia reestructuración de su personalidad en vistas del Hijo. Más que un problema biológico o psicológico, su maternidad es una adhesión obediente en el amor, como recuerda el relato de la anunciación. Fuera cual fuera su precedente proyecto de vida, la intervención de Dios representa un cambio radical: María entra en la lógica del amor de Dios, y se sumerge en la abnegación filial del Verbo aunque, también en esta comunión, mantiene su identidad de criatura y -con ella- su límite respecto al infinito amor de Dios. En ella la superación de sí misma y la vuelta a sí misma se relacionan y se desafían continuamente: son las dinámicas de su vida de gracia. Ayudada por el Espíritu, su vida entera será expresión de esta búsqueda y de este abandono en las manos de Dios.

\subsection{La mediación del Espíritu}

En las Escrituras, la comunión con el Verbo de vida se realiza a través del don del Espíritu que, porque es el Espíritu de Cristo (Rm 8, 9), el Espíritu del Hijo (Gal 4, 6), aparece como quien media en nosotros el acontecimiento-Jesús. Sin recordar ni precisar una serie de pasos bíblicos, podemos decir que el Espíritu realiza una función histórico-salvífica en el corazón del acontecimiento-Jesús, y que las experiencias que los discípulos tienen en base al Espíritu, son diferentes respectos a las que han tenido con Jesús. La tradición las ha resumido en dos experiencias: la del Espíritu huésped del alma y la del Spiritus creator.

Lossky resume la entera tradición cuando recuerda que «el Espíritu se comunica a las personas marcando a cada miembro de la Iglesia con el sigilo de una relación personal y única con la Trinidad, que se hace presente en cada persona» 
(Lossky, 1996) ${ }^{11}$; de manera sugerente, Ignacio escribirá que el Espíritu «es una agua viva que murmura en mí y me dice: ven al Padre» (Ignacio de Antioquía). Además, el Spiritus creator hace del mundo el lugar del futuro, el lugar grávido de posibilidades reales, el lugar de una experimentación concreta de la salvación. En este sentido, la renovación de la vida y del mundo se convierten en innovación y oración, y Veni creator Spiritus es la oración de quien se dirige a Dios dando al futuro la forma del reino de Cristo. El humanismo cristiano se manifiesta como la valentía de fiarse del Espíritu mientras éste manifiesta el eterno "Amén" que Dios ha jurado al mundo y que vincula definitivamente la libertad de Dios a la profundidad de nuestra vida.

Este vínculo de gracia entre Dios y la persona que se abandona en Él encuentra una realización del todo particular en María. Será siempre necesario mantener el vínculo entre esta maternidad y el Espíritu, como recuerdan las Escrituras ${ }^{12}$; de manera sintética, J. Alfaro recordará su sentido cuando observará que «no es María quien hace de Cristo su hijo, sino que es Cristo quien hace de María su madre» (Alfaro, 1983). Para no abandonarse a metafísicas indebidas de la maternidad $^{13}$, deberemos recordar siempre que incluso la singular maternidad de María no es otra cosa sino su modo propio de acoger la gracia salvadora del Hijo, y adherir al papel que el Padre le ha reservado. En este sentido, si se puede hablar del Espíritu en base de una mediación inmediata de Cristo que dura para siempre, se puede hablar de María como de aquella que vive una participación en la participación del Espíritu en la acción redentora de Cristo; pasiva en cuanto al origen, esta su participación está, por el contrario, colma de su fe y de su caridad, hasta el punto de verla como peneumatoforme (Pikaza, 1981).

Quizás se podría añadir algo en la línea del pensamiento de J. D. Scoto, para quien Cristo es summum opus Dei, no querido por algo inferior, sino por sí mismo, por su misma perfección (Rom 8, 18-23); entendido, querido y amado sobre

11 El carácter incondicionado de la libertad humana está en el hecho de que, incluso ante Dios, la libertad de la criatura mantiene una identidad que no se deja disolver; en este sentido, la superación de sí mismos, y la vuelta en sí mismos se entrelaza continuamente con la gracia y con el desafío, mientras ella misma es desafiada.

12 Es la concepción por obra del Espíritu Santo que encontramos en Mt 1, 18. 20; Lc 1, 35.

13 Véase la lectura, para mí inaceptable, de B. Forte, que habla de la maternidad de María como experiencia «hecha partícipe en su ser materno de la "manantialidad" absoluta del Padre», y llega incluso a presentarla como «icono materno del primer Principio de los seres» (B. FORTE, Maria, la donna icona del mistero, p. 235). En la misma medida M. ALONSO, «Trinità», en Nuovo Dizionario di Mariologia, Paoline, Milano 1985, p. 1.413, y S. DE FIORES, «Trinità», en Dizionari San Paolo. 
todas las cosas, el Verbo hecho carne es el eje del designio divino de la creación y de la redención, el centro de toda actividad divina. Al primado de Cristo, Scoto vinculará María summus opus Christi, en el sentido - preservada por gracia y puesta en la condición de plena fidelidad al amor divino- María da voz al anhelo de la creación: en ella la creación vuelve a su Creador como alabanza, acción de gracias y cántico perfecto de amor. Por esto María está llena de una alegría mesiánica45 que retoma y da cauce al anhelo de la creación.

\section{María, Madre de la Iglesia y de la humanidad}

La relación entre mariología y pneumatología se desarrolla, casi naturalmente, en sentido eclesiológico. En efecto, el Vaticano II ha distinguido claramente el acontecimiento-Cristo de aquél del Espíritu, evitando, al mismo tiempo, separarles. El texto decisivo es el de Lumen Gentium 8, que enseña cómo «por esta profunda analogía [la Iglesia] se asimila al Misterio del Verbo encarnado. Pues como la naturaleza asumida sirve al Verbo divino como órgano vivo de salvación indisolublemente unido a Él, de forma no diferente sirve al Espíritu de Cristo como medio para que crezca el cuerpo» ${ }^{14}$.

En este texto, el Vaticano II, toma distancia de aquella eclesiología romántica que, con Möhler, comparaba la Iglesia al «Hijo de Dios que aparece continuamente en forma humana entre los hombres, que siempre se renueva y que eternamente se rejuvenece, su encarnación continua» (Möhler, 1984). El Concilio abandona toda identidad entre Cristo y la Iglesia: por una parte, se habla de "Espíritu de Cristo" vinculando así la obra eclesial con la perspectiva histórico- salvífica, y, por otra, habla del "servicio vivificante" que este Espíritu realiza ante el "organismo social de la Iglesia". El Espíritu es aquí la mediación de Cristo: es decir, el Espíritu «no se sitúa entre nosotros y Cristo casi como un obstáculo, porque él mismo es el vínculo de nuestra correspondencia personal con Cristo» (Mühlen, 1971). El sentido de estas observaciones es el de valorizar la relación compleja y fecunda que asocia María a la obra del Hijo; si Pablo no tiene ningún temor de indicar al apóstol como colaborador de Dios, ¿por qué deberíamos tener miedo de utilizar -según la misma lógica- este término para María? La cooperación de María al designio divino de salvación tuvo lugar «en una posición de

14 Véase el comentario de este texto en H. Mühlen, Una mystica persona, pp. 475-486. 
servicio y de recepción, pero siempre en una posición y función no sustituible» (Scheffczyk, 2002).

Si nos referimos a la relación singular que María tiene con el Espíritu Santo, entonces debemos observar que el Espíritu no es solamente el amor recíproco del Padre y del Hijo, el condilectus, sino que es sobre todo Aquél que hace de su mutua in-existencia «como el espacio ya abierto desde siempre del encuentro interpersonal en persona» (Hilberath, 1996) ${ }^{15}$. Aplicando estos pensamientos en María, no es posible contentarse con una simple y genérica teología de la gracia, sino que es preciso acceder a aquella particular "caridad fraterna" que -como recepción de la caridad trinitario-pascual- cualifica profundamente la personalidad misma de María. Es cuanto H. De Lubac y H. U. von Balthasar indican cuando solicitan abandonar un pensamiento abstracto para retomar con plenitud el símbolo materno como algo central en la comprensión de la Iglesia (Balthasar, 1972) ${ }^{16}$; al contrario, H. Mühlen afirmará que «la maternidad de María es antes que nada y sobre todo una función de servicio en favor de la obra redentora de Cristo, y solamente en segundo lugar es el fundamento de la santidad santificadora de la Virgen misma» (Mühlen, s.f.) ${ }^{17}$.

En otras palabras, el acto salvífico de Dios, realizado por el Verbo y cumplido por el Espíritu, es acogido por María, que, sin intervenir sobre el valor salvífico de la naturaleza humana asumida por el Verbo, es, sin embargo, maternalmente insertada en la dimensión kenótica de la encarnación. Esta elección anticipa y acompaña la personalidad de María, y la estructura en torno a un abandono incondicionado al designio de Dios que, solamente poco a poco, apreciará en la plenitud de sus dinámicas. Si al inicio acepta ser "virgen desposada con un hombre $[. .$.$] de la casa de David» (Lc 1, 27), poco a poco su peregrinatio fidei se$ desarrollará por medio de su consentimiento a las palabras del ángel (Lc 1, 46-47),

15 Ya Tomás, por otra parte - Summa Theologica I, q. 38, a.1 in corpus - opinaba que al Espíritu competit necessario donum esse et dari y lo motivará in quantum est sui ipsius; un comentario más completo de estos pensamientos se pueden encontrar también en Summa Theologica III, q. 30, a. 1 in corpus: Utrum necessarium fuerit annuntiari Beatae Vergini quod in ea erat generandum.

16 Balthasar observará que «en María, la Iglesia que nace de Cristo encuentra su centro personal y la plena realización de su idea eclesial». En esta perspectiva, la maternidad mariana es una gracia cualitativamente diferente de la de los otros fieles, y sitúa a María más allá de aquella tensión entre ideal y realidad que, al contrario, caracteriza a la Iglesia histórica.

17 La afirmación se refiere a la distinción que Mühlen pone entre "consagración" y "santificación": la primera habilita a María a un papel histórico-salvífico que se refiere a la entera historia humana, mientras que la segunda tiene un valor personal. 
el no comprender las actitudes desconcertantes de aquél hijo, sino confiar el no entender a la custodia y a la meditación en el propio corazón ${ }^{18}$, la intuición de una nueva alianza testimoniada en la profesión de fe de Caná (Jn 2, 3-5), y, sobre todo, su presencia a los pies de la cruz (Jn 19, 25-27) y en el cenáculo de Pentecostés (Hch 1, 14). Su humanidad está de tal manera determinada por esta experiencia, que Lucas la llamará kekaritoméne, llena de gracia; comentando ese conjunto de cosas, Alfaro observará que «la gracia de María y la gracia de su contribución a la salvación de la humanidad se identifican: son la gracia absolutamente singular que María ha recibido de Cristo (Alfaro, s.f.).

\subsection{María y la Iglesia}

Enumerando los elementos estructurales de la actuación del Evangelio de gracia, E. Schillebeeckx indica cuatro: la historia salvífica universal de la relación de Dios con el hombre; su manifestación en la persona y en la vida de Jesús; la historia de los cristianos que viven siguiendo a Jesús; y la continuación de la historia hacia un fin que no es de este mundo (Schillebeeckx, 1980); de estos cuatro puntos, quisiera referirme aquí, en la práctica, a los dos últimos. No es casualidad, comentando el valor del "memorial bíblico" y desarrollando el zikkaron en el sentido profundo de una memoria Jesu, Schillebeeckx observa que «la única auténtica reliquia de Jesús es la comunidad viva», y la desarrolla en una línea pneumatológica e histórica (Schillebeeckx. s.f.).

Estas indicaciones hay que completarlas con la sugerencia de Th. Pröpper que, hablando de un "olvidado camino de Jesús", invitará a no concentrar la soteriología solamente en torno de la cruz, sino a desarrollar una valoración global de la personalidad de Jesús y de su humanidad, sin verla solamente como camino hacia la cruz (Pröpper, 1990) ${ }^{19}$. Al ofrecer alguna alusión a una eclesiología mariana, es necesario partir del hecho de que María y la Iglesia no son simplemente intercambiables: entre ellas continúan existiendo las diferencias. Más allá de la distinción de Balthasar entre una Iglesia petrina, es decir, jerárquica e

18 Para el no entender de María cfr. Lc 2, 50, el texto discutible de Mc 3, 21. 31-35 y aquél enigmático de Lc 2, 34-35; para la custodia en el corazón cfr. Lc 2, 19. 51.

19 Obviamente aquí está en juego la comprensión histórica de las doctrinas soteriológicas; sobre esto, véanse también H. KESSLER, Die theologische Bedeutung des Todes Jesu. Eine traditionsgeschichtliche Untersuchung, Patmos, Düsseldorf 1971, pp. 21-165; G. GRESHAKE, «La trasformazione delle concezioni soteriologiche nella storia della teologia», en AA.VV., Redenzione ed emancipazione [1973], Queriniana, Brescia 1975, pp. 83-130. 
institucional, y una Iglesia mariana, es decir, mistérica y esponsal (Balthsar, 1976), permanece el hecho de que la Iglesia supone el acontecimiento-Cristo como algo ya realizado, mientras que María ha cooperado maternalmente al cumplimiento mismo de ese acontecimiento. María anticipa y representa la Iglesia en la línea de aquella "precedencia" mariana de la que hablan Redemptoris Mater 3. 6: María "precede" el pueblo de Dios, porque, como madre y virgen, precede la venida del Salvador e introduce a él.

Aunque María representa «la plenitud de la existencia de la Iglesia», dado que «ejerce una función universal a favor de toda la Iglesia» (Alfaro, s.f.), será necesario tener en cuenta del hecho de que, por una parte, está dentro de la Iglesia como miembro y, por otra parte la acoge sintéticamente en sí hasta el punto de que es el typus «en el orden de la fe, de la caridad y de la perfecta unión con Cristo» (LG 63). Desarrollando esta relación en términos esponsales, H. De Lubac cita una discreta serie de autores que identifican la esposa del Cántico de los Cánticos no solamente en la Iglesia, sino en María, y describe el vínculo esponsal entre el Verbo y María (De Lubac, 1963) ${ }^{20}$; en efecto, dirá Dionisio el Certosino, «buscan el Verbo de Dios con mucha mayor perfección, con mayor fruto y con mayor afecto quienes ya lo poseen que quienes no lo poseen» (Dionisio il Certosin, 1989). Comentando este hecho, Balthasar observará que «debe ser siempre un punto firme que el acto eclesial subjetivo, incluso en su máxima plenitud mariana, continúa siendo un acto de dedicación femenina, acto no de dominio soberano -que le corresponde a la Cabeza- sino de humilde disponibilidad y docilidad propia de la sierva» (Balthasar, s.f. $)^{21}$.

Un último aspecto se refiere al hecho de que la plenitud de la gracia, leída anteriormente en la perspectiva de una comunión mística con Cristo, acentúa hoy su dimensión histórica: el reino es el horizonte fundamental de la gracia.

20 Dionisio el Certosino escribirá «triplex est sponsa Christi, vide licet: tota universalis Ecclesia, quae vocatur sponsa... generalis; et quaelibet anima fidelis et amorosa, quae dicitur Christi sponsa particularis; itemque beatissima Virgo Maria Christifera, quae Christi sponsa censetur» (DIONISIO IL CERTOSINO, «In Cantica - Proemium», en Id., Opera omnia. VII, S. M. De Pratis \& Tornaci, Monstrolii 1898, p. 201).

21 Como comentario ulterior, véase el texto precedente: «el acto mariano se convierte por excelencia en el acto subjetivo fundamental de la Iglesia, precisamente, de manera que el acto personal-mariano, en virtud de su unicidad y de su eminencia, puede ser contemporáneamente dos cosas: el fundamento subjetivo plenamente realizado por el acto subjetivo de la Iglesia en cuanto tal [...] y, dado que María es también una creyente al interno de la comunión eclesial, el fundamento subjetivo plenamente realizado de cada acto personal de fe al interno de la communio sanctorum» (ivi, pp. 161-162). 
Efectivamente, en su misión Cristo no se anuncia a sí mismo ni a Dios, sino la venida del reino: considerado en su objetividad, el reino impide pensar y vivir la historia separada de Dios. En este sentido, las oposiciones entre inmanencia y trascendencia, entre espiritual y corpóreo, entre interior y público, entre personal e institucional resultan superadas. El reino de Dios, entendido como acontecimiento dinámico, se contrapone con la realidad histórica del pecado y con el mundo de relaciones que de esto se derivan. «La naturaleza del reino es la comunión de todos los seres humanos entre ellos y con Dios» (RM 15).

\subsection{María y la humanidad}

No se pueden comenzar estas palabras finales sin recordar la observación de Tomás cuando, comentando que la anunciación se dirige al spirituale matrimonium inter Filium Dei et humanam naturam, observa que el consenso de María es dado loco totius humanae naturae (de Aquino, s.f.). Si el ascenso es dado en nombre de la humanidad entera y no solamente en nombre de la Iglesia, es porque María representa toda la humanidad. Rahner observará que María no solamente se encuentra en el momento central de la historia de la salvación, sino que, en este acontecimiento tan singular, esta mujer, "“co-ayudada" y rodeada por la gracia, acoge esta misma gracia para sí misma y para los otros, de modo que la aceptación de esa gracia a título personal llega a constituir la salvación de los otros; no hay que insistir, además, en que la aceptación, la colaboración con la salvación de otros es precisamente el acto en el que la gracia de Dios es acogida a título personal, de manera que servicio ministerial y santidad individual se unen hasta convertirse en un elemento único» (Rahner, 1964).

Este discurso merecería un desarrollo largo y amplio. Siendo imposible hacerlo aquí, me limitaré a recordar dos trabajos relativamente recientes que entran en el mérito de estos problemas. El primero es la obra de E. Johnson, y se refiere a la problemática de la mujer (Johnson, 2005). La propuesta de Johnson es presentar a María como «un ser humano concreto, con su último destino personal en Dios» (Johnson, 2005). Aún reconociendo que la figura de María, así como la propone la fe cristiana, es particularmente oportuna para llegar a ser el punto final de proyecciones simbólicas relativas a la vida virtuosa o a un determinado ideal de mujer ${ }^{22}$, la autora se propone, sobre todo, desarrollar el conocimiento

22 Johnson ve la simbología mariana al servicio de la vida de fe, y la describe como realidad creada «por la experiencia de la Iglesia con un Dios de gracia» (E. JOHNSON, Vera nostra sorella, p. 197). 
del contexto histórico en el que María está integrada, y, basándose en las consecuencias de la piedad mariana en la vida de las mujeres, clarifica, después, la vocación de María como contemplación de la solicitud divina por el mundo y como ministerio en favor de un estilo de vida solidario con esta manera de amar (Johnson, 2005). Una tal perspectiva, diferente de las que las Iglesias practican tradicionalmente, exige mayor conciencia crítica por parte de todos, incluido aquél feminismo, típico de grupos intelectualmente dominantes, que pretende universalizar la propia manera de interpretar la vida como la única realmente aceptable.

La segunda obra se mueve en la línea de la teología de la liberación (Colzani, 2007), y es la obra de Cl. Boff (Boff, 2007). Desde su título, la obra se propone una revisión de la mariología en términos sociales, lo que supone tanto una toma de distancia y una crítica respecto al significado y a la incidencia social de la precedente piedad mariana, como una nueva y diferente elaboración de esa piedad. Motivando su opción y clarificando el vínculo que pretende desarrollar entre fe mariana y vida social, el autor recuerda cómo «el locus de ejercicio de la mariología social no se puede reducir a las sedes académicas, sino que es también y sobre todo la comunidad eclesial en cuanto actúa en el mundo. El Sitz im Leben de la mariología social es la misma Iglesia en la medida en que vive la piedad mariana y, al mismo tiempo, se compromete en lo social» ${ }^{23}$. Profundizando las bases bíblicas de este discurso, se puede recordar -con Cl. Boff- el texto del Magníficat (Boff, 2007), sobre todo los versículos de Lc 1, 51-53, pero no olvidaría ni las bienaventuranzas (Ellacuría, 1992) ni la valoración bíblica de la pobreza (Ellacuría, s.f.). La fuerza cultural del símbolo mariano explica tanto la necesidad de entender el papel que esta fe ejerce en la historia, la necesidad de una toma de conciencia de eventuales ambigüedades, como el compromiso por encauzar estas energías culturales de la fe a lo largo de cauces que valgan la pena. Es evidente que, para el autor, este proceso es un proceso evangélico y ético tal como se da en la opción fundamental por los pobres, en las opciones de la teología de la liberación. En este sentido, el autor desarrollará los dogmas marianos en la línea de la promoción de la vida y de la dignidad de las personas.

23 Es tesis habitual de la teología de la liberación que existe un vínculo estrecho entre el "dónde" y el "cómo" de la teología; es necesario añadir que la vida de Clodovis Boff ha sido un testimonio espléndido de esta opción. 


\section{Conclusión}

Esta visión de la gracia se manifiesta más allá de cualquier ruptura entre oikononía y theología: valorizando el discurso trinitario como fundamento y criterio de la economía salvífica, llega a una revisión de la salvación basándose en la centralidad del don de la vida divina, pero también en el encuentro de este don con la libertad propia de las criaturas. La referencia al dato cristológico es aquí espontánea e inevitable; en encuentro entre las tesis scotistas y las teilhardianas (Beer, 2008) introducen una lectura de la historia donde la gracia se convierte en fuerza y energía social, cultural y política.

Aplicados a María, estos elementos explican su pertenencia a la historia de la manifestación del Dios que ha querido el mundo con un acto creador libre, pero lo ha querido desde siempre para la comunión plena con Él. En esta lectura scotista-teilhardiana la figura de María aparece marcada por un tal abandono total que hace de él el fundamento de una libertad llamada a secundar de una manera muy particular el designio de Dios. Su experiencia del Dios de gracia es totalmente diferente de una simple visión religiosa del mundo o de una especulación teísta sobre la historia: su contenido no procede de una reflexión inteligente, sino de una palabra de promesa y de un acontecimiento de salvación que, si por una parte pueden ser escándalo contra el que se enfrenta nuestro orgullo y nuestra voluntad de autonomía, son sin embargo el ámbito de un camino singular de adhesión a Dios. Su ser personal será «desprivatizado, socializado y transformado en un espacio y fundamento de comunidad» (Balthasar, 1983) en el sentido que «el lugar de esta comunidad es ocupado personalmente, en la forma más concreta, por la madre de Jesús, la cual, en su misión es de tal modo también la madre de sus hermanos» (Balthasar, 1983).

Quizás, el autor que más avanzará en esta línea será M. Kolbe que, aún manteniendo a María en el discipulado de Cristo, ofrecerá una relectura mística del cristocentrismo teilhardiano y, sobre la base de una historia recapitulada totalmente en Dios, hará de María el fruto más alto de la gracia, la síntesis de la tensión que recorre toda la creación. La perspectiva de Kolbe, en mi opinión, se centra menos en la proclamada quasi-encarnación ${ }^{24}$-como parecía que pensaba

24 La referencia es a ciertos pasajes de las conferencias del 27 de junio de 1936 y del 24 de noviembre de 1938 y a la Nota del 1938 en la que escribe icásticamente en latín: «Filius incarnatus est: Iesus Christus. Spiritus Sanctus quasi incarnatus est: Immaculata». 
L. Boff ${ }^{25}$ - sino que vierte sobre todo sobre la comunión de María con el Espíritu que realiza en ella una misión precisa; instrumento personal, es decir, libre y consciente del Espíritu, María es la cumbre de la creación que vuelve a Dios (Kolbe, 1975). «En la unión del Espíritu Santo con María no solamente el amor une estas dos Personas, sino que el primero de ellos es todo el amor de la Santísima Trinidad, mientras que el segundo es todo el amor de la creación.

Así, en una tal unión el cielo se une con la tierra, todo el amor increado con el amor creado; es la cumbre del amor» (Kolbe, 1975).

\section{Referencias}

Werbick, J. (1993). La crisi della soteriologia, en Id., Soteriologia [1990], Queriniana: Brescia,

Bosch, D. (2000). La trasformazione della missione. Mutamenti di paradigma in missiologia [1991], Queriniana: Brescia.

Colzani, G. (2001). Antropología Teológica. El hombre: paradoja y misterio [1997], Secretariado Trinitario: Salamanca.

Kasper, W. (1990). Natur-Gnade-Kultur. Zur Bedeutung modernen Säkularisierung, «Theologische Quartalschrift» 170.

Galindo, J. A. (1991). El tratado «de Gratia» en la Teología actual, «Escritos del Vedat»21,

Colzani, G. (1993). Il trattato «De gratia». Presentazione storico-bibliografica, «Vivens Homo» 4.

García, C. (1993). La Teologia postconciliar sobre la gracia, «Burgense» 34, 1.

Henry, M. (1994). Les diverses courants de la théologie de la grâce aujourd'hui, «Revue de l'Institut Catholique de Paris» 51.

Nicolas, J. H. (1995). Les rapport entre nature et le surnaturel dans les débats contemporaines, «Revue Thomiste» 95

Gironés, G. (1996). En torno al Tratado de Gracia, «Anales Valentinos» 22

Morali, I. (2001). «De rationibus re-instituendi tractatum de gratia». La teologia della grazia tra storia e prospettiva, «Sapienza» 54, 1

25 El quasi ipostatico tendrá un eco clamoroso en L. BOFF, Il volto materno di Dio. Saggio interdisciplinare sul femminile e le sue forme religiose, Queriniana Brescia 1981; en este texto avanza la hipótesis de que «la Virgen María, madre de Dios y de los hombres, realiza lo femenino en forma escatológica y absoluta, porque el Espíritu Santo ha hecho de ella su templo, su santuario y su tabernáculo, de manera talmente real y verdadera que ella debe ser considerada como unida hipostáticamente a la tercera Persona de la S.S. Trinidad» (ivi, p. 93). 
Colombo, G. (1977). «Il Soprannaturale», en Dizionario Teologico Interdisciplinare. III, Marietti: Torino

Colzani, G. (2003). «Escatologia e teologia della storia», en G. CANOBBIO - P. CODA (editores), La Teologia del XX secolo. Un bilancio. II: Prospettive sistematiche, Città nuova: Roma

Mühlen, H. (1968). «La dottrina della grazia», en Vander Gucht, R. \& Vorgrimler, H. (editores), Bilancio della teologia del XX secolo. III: Le discipline teologiche. L'avvenire della teologia, Città nuova, Roma, pp. 161-210,

Mühlen, H. Una mystica persona. La Chiesa come il mistero dello Spirito santo in Cristo e nei cristiani: una persona in molte persone [1967], Città nuova: Roma.

Duquoc, Ch. (1978). Un Dio diverso. Saggio sulla simbolica trinitaria [1977], Queriniana: Brescia.

Congar, Y. (s.f.) Credo nello Spirito santo. III: Il fiume di vita (Ap 22, 1) scorre in Oriente ed in Occidente. Teologia dello Spirito santo, Queriniana, Brescia.

Philips, G. (1969). La Chiesa e il suo mistero nel Concilio Vaticano II. Storia, testo e commento della Costituzione "Lumen Gentium". II [1967], Jaca Book, Milano.

Forte, B. (1989). Maria, la donna icona del mistero. Saggio di mariologia simboliconarrativa, Paoline, Cinisello Balsamo (MI).

Schürmann, H. (1983). Il vangelo di Luca. I, Paideia, Brescia,

Cantalamessa, R. (1989). Maria. Uno specchio per la Chiesa, Ancora, Milano 1989.

Moltmann, J. (1992). Lo Spirito della vita. Per una pmeumatologia integrale [1991], Queriniana, Brescia 1994, p. 100. GUTIÉRREZ, (1992) G. Il Dio della vita, Queriniana, Brescia.

Lossky, V. (1867). La teologia mistica della Chiesa d'Oriente, Bologna 1967, p. 160. Tomás dirá lo mismo cuando, siguiendo a Agustín, sostendrá que el término "don" es un nombre.

Ignacio De Antioquía, Ai Romani 7; PG 5, 689.

Alfaro, J. (1983). Maria. Colei che é beata perché ha creduto, Piemme, Casale Monferrato (AL).

Alonso, M. (1985). «Trinità», en Nuovo Dizionario di Mariologia, Paoline, Milano 1985, y De Fiores, S. «Trinità», en Dizionari San Paolo.

Mühlen, H. (1971). «L'evento di Cristo come atto dello Spirito santo», en J. Feiner - MLöhrer Mysterium salutis. VI, Queriniana, Brescia.

Scotus, I. D. (1933). Reportatio Parisisensis A III, d. 7, q. 4., en Id., Theologiae marianae elementa quae ad fidem codd. mss., editado por C. BALIC, Tip. Kacic, Sibenici.

Möhler, J. A. (1984). Simbolica. Esposizione delle antitesi dogmatiche tra cattolici e protestanti econdo i loro scritti confessionali pubblici [1838], Milano, Jaca Book. 
Scheffczyk, L. (2002). Maria, crocevia della fede cattolica, Eupress SA, Pregassona (Lugano).

Hilberath, B. J. (1996). Pneumatologia [1994], Queriniana, Brescia.

Von Balthasar, H. U. (1972). «Chi è la Chiesa?», en Id., Saggi teologici. II: Sponsa Verbi, Morcelliana, Brescia.

Schillebeeckx, E. (1980). Il Cristo. La storia di una prassi, Queriniana, Brescia 1980.

Pröpper, Th. (1990) Redenzione e storia della libertà. Abbozzo di soteriologia [1985], Queriniana, Brescia.

Kessler, H. (1971). Die theologische Bedeutung des Todes Jesu. Eine traditionsgeschichtliche Untersuchung, Patmos, Düsseldorf,

Greshake, G. (1975). «La trasformazione delle concezioni soteriologiche nella storia della teologia», en AA.VV., Redenzione ed emancipazione [1973], Queriniana, Brescia,

Von Balthasar, H. U. (1976). «L'amour maternel enveloppant de l'Église», en Id., Le complexe antiromain. Essai sur les structures ecclésiales, Apostolat des Éditions - Éditions Paulines, Paris.

De Lubac, H. (1963). «La Madonna e la Chiesa», en Id., Meditazione sulla Chiesa, Paoline, Milano.

Dionisio Il Certosino, (1898). «In Cantica - Proemium», en Id., Opera omnia. VII, S. M. De Pratis \& Tornaci, Monstrolii..

De Aquino, S. T. Summa Theologica. III, q. 30, a. 1, in corpus.

Rahner, K. (1964). «Riflessioni teologiche sui problemi fondamentali della cura d'anime. III: Maria tipo dell'apostolato e dell'azione pastorale», en Id., Missione e grazia. Saggi di teologia pastorale, Ed. Paoline, Roma..

Johnson, E. (2005). Vera nostra sorella. Una teologia di Maria nella comunione dei santi [2003], Queriniana, Brescia.

Colzani, G. (2007). «La libertà cristiana. Energia di liberazione e di riconciliazione», en Id., Missiologia contemporanea. Il cammino evangelico delle Chiese: 1945- 2007, San Paolo.

Boff, Cl. (2007). Mariologia sociale. Il significato della Vergine per la società, [2006], Queriniana, Brescia.

Ellacuria, I. (1992). «Le beatitudini, carta di fondazione della Chiesa dei poveri», en Id., Conversione della Chiesa al regno di Dio. Per annunciarlo e realizzarlo nella storia [1984], Queriniana, Brescia

Ellacuria, I. (s.f.) «I poveri, "luogo teologico" in America Latina», en Id., Conversione della Chiesa al regno di Dio.

De Beer, F. (2008). «La primauté inconditionnelle du Christ chez Jean Duns Scot. Convergences avec le Père Teilhard de Chardin», en Carbajo Nuñez, M. (editor), 
Giovanni Duns Scoto. Studi e ricerche nel settimo centenario della sua morte. In onore di P. César Saco Alarçon, Edizioni Antonianum, Roma,

Von Balthasar, H. U. (1983). Teodrammatica. III: Le persone del dramma: l'uomo in Cristo, Jaca Book, Milano.

Kolbe, M. (1975-1978). Gli scritti di Massimiliano Kolbe eroe di Oswiecim e Beato della Chiesa. 3 voll, Città di vita, Firenze.

Boff, L. (1981). Il volto materno di Dio. Saggio interdisciplinare sul femminile e le sue forme religiose, Queriniana Brescia.

Kolbe, M. Gli scritti di Massimiliano Kolbe, III... 